\title{
Olfactory Preservation in Craniofacial Resection of Tumor Invading Hemianterior Skull Base: Operative Video
}

\author{
Kenya Kobayashi ${ }^{1}$ Yasuji Miyakita ${ }^{2}$ Fumihiko Matsumoto ${ }^{1}$ Go Omura ${ }^{1}$ Satoko Matsumura ${ }^{1}$ \\ Atsuo Ikeda ${ }^{1}$ Kohtaro Eguchi ${ }^{1}$ Akiko Ito ${ }^{1}$ Yoshitaka Narita ${ }^{2}$ Satoshi Akazawa ${ }^{3}$ Seiichi Yoshimoto ${ }^{1}$ \\ ${ }^{1}$ Department of Head and Neck Surgery, National Cancer Center \\ Hospital, Tokyo, Japan \\ 2 Department of Neurosurgery and Neuro-oncology, National Cancer \\ Center Hospital, Tokyo, Japan \\ Address for correspondence Kenya Kobayashi, MD, PhD, Department \\ of Head and Neck Surgery, National Cancer Center Hospital, 5-1-1 \\ Tsukiji, Chuo-ku, Tokyo 104-0045, Japan \\ (e-mail: kenyajp@hotmail.com).
}

${ }^{3}$ Department of Plastic and Reconstructive surgery, National Cancer

Center Hospital, Tokyo, Japan

J Neurol Surg B Skull Base 2022;83(suppl S3):e639-e640.

\begin{abstract}
Keywords

- olfactory preservation

- craniofacial resection

- hemianterior skull base

- ethmoid sinus

- craniotomy

In traditional craniofacial resection of tumors invading the anterior skull base, the bilateral olfactory apparatus is resected. Recently, transnasal endoscopy has been used for olfactory preservation in resections of unilateral low-grade malignancies. However, for tumors that invade the orbita or for high-grade malignancies, the transnasal endoscopic skull base surgery has been controversial. This video demonstrates the surgical techniques of olfactory preservation during craniofacial resection of a highgrade malignancy invading the hemianterior skull base and orbita.

We present the case of a 32-year-old woman with osteosarcoma in the right ethmoid sinus. The tumor invaded the ipsilateral cribriform plate, dura menta, and orbital periosteum; however, the nasal septum and crista galli were intact ( $\mathbf{F i g . 1 A}$, B). Because the tumor was a high-grade malignancy and the orbita had been invaded, we performed craniofacial resection instead of endoscopic resection (-Fig. C2A). We drilled into the right side of the crista galli, midline of the cribriform plate, and perpendicular plate of the ethmoid bone via craniotomy. As a result, we accessed the nasal cavity directly (-Fig. 2B). To preserve the nasal septum, we detached the remaining right septal mucosa through the transfacial approach (-Fig. 2C). Because of the high risk of cerebrospinal fluid leakage as a result of previous irradiation, we performed vascularized free flap reconstruction of the skull base instead of pericranial flap.
\end{abstract}

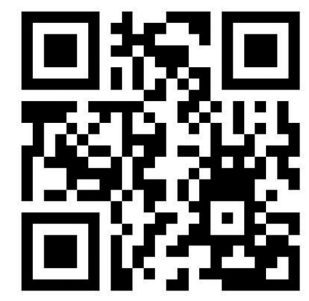

received

June 9, 2020

accepted after revision

January 7, 2021

published online

May 23, 2021

\section{Funding}

This work was supported by the Japan Society for the Promotion of Science (JSPS) KAKENHI Grant, grant number: 19 K09923.

Conflict of Interest

None declared.

www.thieme.com/skullbasevideos

www.thieme.com/jnlsbvideos

DOI https://doi.org/

10.1055/s-0041-1727123. ISSN 2193-6331.

\footnotetext{
(C) 2021. The Author(s).

This is an open access article published by Thieme under the terms of the Creative Commons Attribution-NonDerivative-NonCommercial-License, permitting copying and reproduction so long as the original work is given appropriate credit. Contents may not be used for commercial purposes, or adapted, remixed, transformed or built upon. (https://creativecommons.org/ licenses/by-nc-nd/4.0/) Georg Thieme Verlag KG, Rüdigerstraße 14, 70469 Stuttgart, Germany
} 

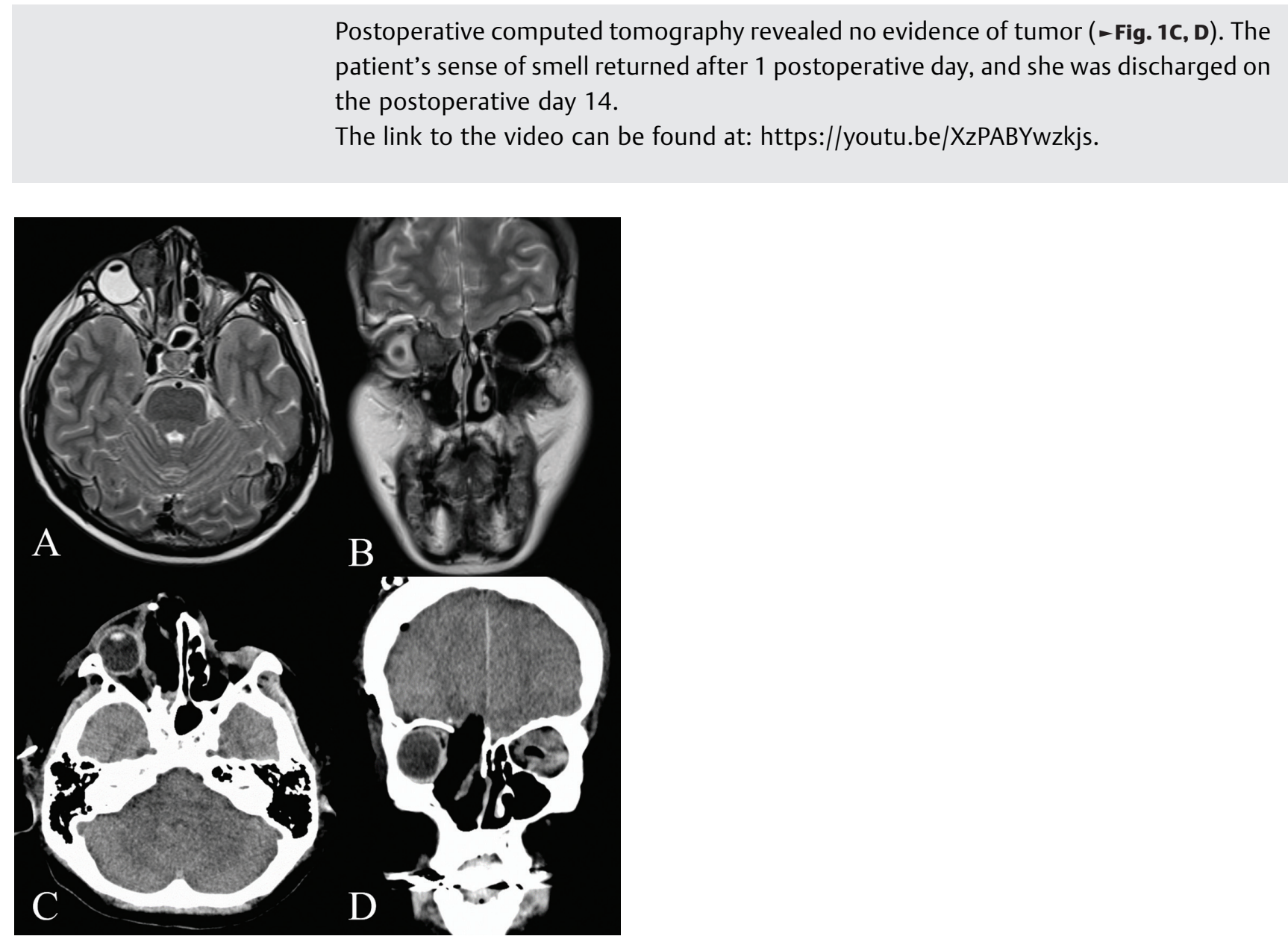

Fig. 1 Preoperative axial (A) and coronal (B) T2-weighted magnetic resonance images demonstrating a $2 \mathrm{~cm} \times 2 \mathrm{~cm} \times 2 \mathrm{~cm}$ well-circumscribed tumor invading the ipsilateral cribriform plate, dura menta, and orbital periosteum; the nasal septum was intact. Postoperative axial (C) and coronal (D) computed tomographic images demonstrating that the tumor was completely resected and the left olfactory apparatus (epithelium, cribriform plate, and olfactory bulb) were spared.

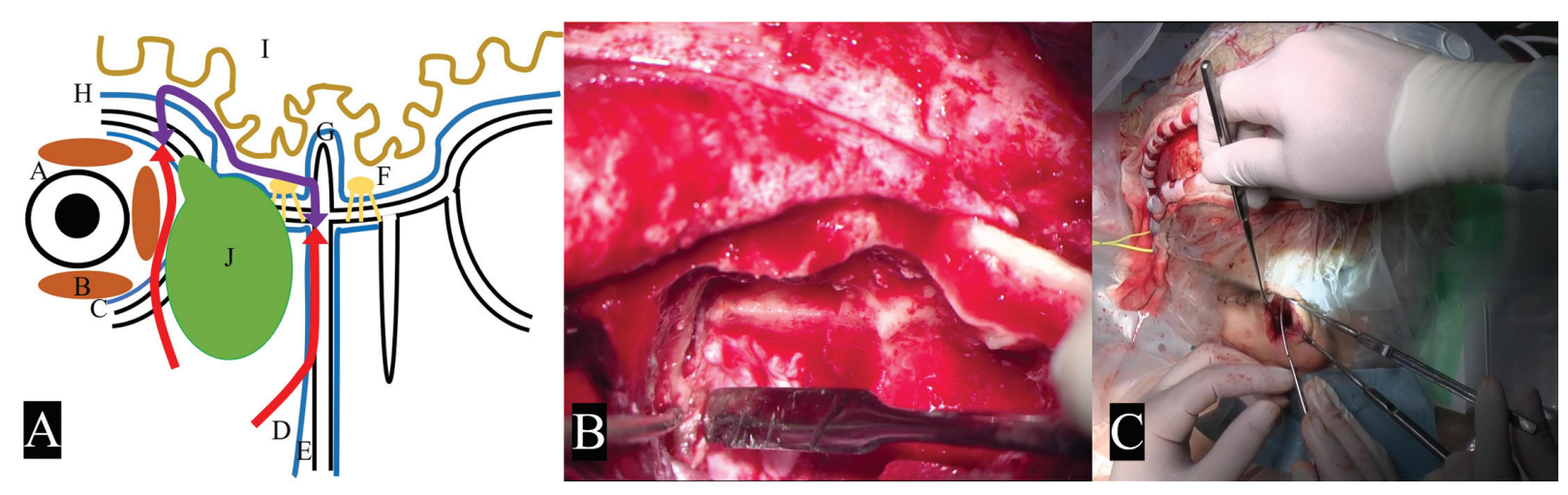

Fig. 2 The scheme of surgical resection is shown (A). Purple arrow indicates the line of dissection in the transcranial approach. Red arrow indicates the line of dissection line in the transfacial approach. A, eyeball; B, extraocular muscle; C, orbital periosteum; D, septum mucosa; $E$, septum cartilage; F, olfactory bulb; G, crista galli; H, dura mater; I, brain; J, tumor. (B) Intraoperative image showing the midline of the cribriform plate and the perpendicular plate of the ethmoid bone were drilled via craniotomy, and (C) the right septal mucosa were detached through the transfacial approach. 